\title{
Effect of high pressure on microstructure of cast Mg-8Zn-0.5Zr-0.5Gd alloy
}

\author{
${ }^{*}$ Dong-song Yin ${ }^{1}$, Yun-long Zhang ${ }^{2,3}$, Yong-liang An ${ }^{1}$, Zhen-ling Wang ${ }^{1}$, Yun-zhou Hu ${ }^{1}$, and Ai-lian Liu ${ }^{1}$ \\ 1. College of Materials Science and Engineering, Heilongjiang University of Science and Technology, Harbin 150022, China \\ 2. School of Materials Science and Engineering, Harbin Institute of Technology, Harbin 150001, China \\ 3. College of Materials Science \& Engineering, Jiamusi University, Jiamusi 154007, China
}

\begin{abstract}
Mg-8Zn-0.5Zr-0.5Gd alloy was prepared by high pressure solidification. Effect of high pressure on microstructure, micro-hardness and corrosion behavior in Hank's solution of the Mg-8Zn-0.5Zr-0.5Gd alloy were investigated by means of optical microscopy (OM), scanning electron microscopy (SEM), energy dispersive spectroscopy (EDS), and X-ray diffractometer (XRD). The results showed that, compared with the conventional solidification, high pressure solidification obviously refined the grain size of $\mathrm{Mg}-8 \mathrm{Zn}-0.5 \mathrm{Zr}-0.5 \mathrm{Gd}$ alloy. The grain size was refined from 200-300 $\mu \mathrm{m}$ to $100-200 \mu \mathrm{m}$ and the secondary dendrite arm spacing reduced from 30$50 \mu \mathrm{m}$ to $10-30 \mu \mathrm{m}$. Moreover, the solubility of $\mathrm{Zn}$ in the alloy increased and the amount and size of $\mathrm{Mg}-\mathrm{Zn}-\mathrm{Gd}$ phases significantly decreased. The micro-hardness of the alloy solidified under high pressure was improved significantly from $56.17 \mathrm{HV}$ to $63.14 \mathrm{HV}$. The polarization resistance $\left(R_{\mathrm{p}}\right)$ of the alloy had a substantial increase in simulated body fluid, thus the corrosion rate was significantly reduced from 4.0 to $2.7 \mathrm{~mm} \cdot y e a r^{-1}$.
\end{abstract}

Key words: magnesium alloy; high pressure solidification; microstructure; corrosion rate; micro-hardness
CLC numbers: TG146.22
Document code: A
Article ID: 1672-6421(2017)01-022-06

$\mathrm{M}$ agnesium alloy has unique bio-compatibility and elasticity modulus close to that of human bones. Therefore it can avoid the "stress shielding" effect and secondary surgery owing to bio-degradation in body fluids. However, magnesium alloy faces challenges in meeting some special requirements because of its poor corrosion resistance and ductility ${ }^{[1-3]}$. In order to improve the corrosion resistance of magnesium alloys, several efforts have been made such as $\mathrm{Zn}$ alloying method, which can improve the corrosion resistance in body fluids and the strength of the magnesium alloy ${ }^{[4,5]}$. Heat treatment can also improve corrosion resistance of magnesium alloy in body fluids through reducing or eliminating the negative effects of cathode relative corrosion. The deforming process can eliminate shrinkages of alloy and refine grain structure, which enhance corrosion resistance and mechanical properties ${ }^{[6,7]}$. Surface treatments including micro arc oxidation, anodizing, laser modification, electrophoresis, and electro-deposition etc. can

\footnotetext{
*Dong-song Yin

Male, born in 1974, Ph. D., Associate professor. His research interest mainly focuses on the magnesium alloys. To date, he has published 16 technical papers.

E-mail: dongsongyin@126.com
}

Received: 2016-04-21; Accepted: 2016-12-26 significantly reduce corrosion rate of magnesium alloy in body fluids, but it cannot improve mechanical properties.

High pressure solidification is one of the new recent technologies. It can change the distribution of second phase, uniformity of composition and obtain non-equilibrium microstructure, due to the decrease of diffusion coefficient with increasing loading pressure. When the pressure reaches GPa level, it changes the thermodynamic and kinetic conditions in the alloy solidification process dramatically ${ }^{[8,9]}$. During the solidification process, the diffusion coefficient of solute for metals and their alloys decreases under the effect of high pressure, so it results in a decrease in growth speed of the crystal nucleus and the spacing of secondary dendrite. As a result, the grain size of the precipitated phase reduces ${ }^{[10,11]}$. It has been reported that the self corrosion current of AZ91D magnesium alloy significantly decreased after high pressure solidification at $1,000{ }^{\circ} \mathrm{C}$ and $3 \mathrm{GPa}$, followed by air cooling to room temperature ${ }^{[12]}$. Results showed that high pressure solidification can reduce the size of precipitated phase in the alloy substrate, and thereby it can weaken local galvanic corrosion of magnesium alloys and improve corrosion resistant performance. The corrosion resistance of Mg-30Al and Mg-7Y- 
$0.5 \mathrm{Zn}$ alloy after high pressure solidification is better than that of alloys solidified at normal pressures ${ }^{[13,14]}$. However, research reports about high pressure solidification are still relatively rare. In this paper, the effect of high pressures on the microstructure, microhardness and corrosion behavior of $\mathrm{Mg}$ $8 \mathrm{Zn}-0.5 \mathrm{Zr}-0.5 \mathrm{Gd}$ magnesium alloy in simulated body fluid were investigated. This research will explore the evolution behavior of the microstructure and properties of $\mathrm{Mg}-8 \mathrm{Zn}$ $0.5 \mathrm{Zr}-0.5 \mathrm{Gd}$ magnesium alloy after high pressure treatment. The research results will provide reference for the preparation of medical magnesium alloys by high pressure technology.

\section{Experimental procedure}

The samples solidified at normal pressures were prepared as follows: $\mathrm{Mg}-8 \mathrm{Zn}-0.5 \mathrm{Zr}-0.5 \mathrm{Gd}$ alloy was melted with high purity $\mathrm{Mg}$ (99.99wt.\%), high purity Zn (99.99wt.\%) and Mg30wt.\%Gd master alloy as starting materials in an crucible resistance furnace at $730-800{ }^{\circ} \mathrm{C}$ with mixed gas $\left(\mathrm{CO}_{2}+0.5 \%\right.$ $\mathrm{SF}_{6}$ ) protection. The liquid metal was stirred for $5 \mathrm{~min}$ and held for $15 \mathrm{~min}$ before poured into a graphite mold which was preheated to $200{ }^{\circ} \mathrm{C}$. The measured composition of $\mathrm{Mg}-8 \mathrm{Zn}$ $0.5 \mathrm{Zr}-0.5 \mathrm{Gd}$ alloy is shown in Table 1 .

Table 1: Chemical composition of Mg- $6 \mathrm{Zn}-0.5 \mathrm{Zr}-0.5 \mathrm{Gd}$ alloy (wt.\%)

\begin{tabular}{ccccccccc} 
Mn & Zn & Zr & Gd & Fe & Ni & Cu & Mg \\
\hline 0.13 & 8.2 & 0.45 & 0.53 & $<0.01$ & $<0.005$ & $<0.005$ & Bal.
\end{tabular}

The Mg-8Zn-0.5Zr-0.5Gd alloy was also prepared under the same conditions except high pressure solidification. The schematic illustration of high pressure solidification is shown in Fig. 1. The high pressure device is a CS-1B six-anvil apparatus, which has six anvils to squeeze the sample to achieve quasihydrostatic pressure. The applied pressure was about $4 \mathrm{GPa}$. The specimens with dimension $\Phi 5 \mathrm{~mm} \times 10 \mathrm{~mm}$ were wrapped by $\mathrm{BN}$ powders, and then put into the graphite sleeve while the circular graphite sheet was applied at opposite ends of the graphite sleeve. The graphite sleeve with wrapped specimen was placed in the hexahedral pyrophillite bulk. Then the pyrophillite bulk together with the specimen was put into the high pressure apparatus. A sealed graphite tube was put into the middle hole of the pyrophyllite block and a conductive ring was placed at each end of the graphite tube to heat the specimen. To measure the temperature, a straight-through hole was punched at the corner of the pyrophyllite block and a thermocouple wire was inserted into the block to make contact with the specimen. The other end of the thermo-couple was connected with the temperature recording devices. The sample was rapidly heated to $980{ }^{\circ} \mathrm{C}$ and held for $30 \mathrm{~min}$ to ensure the alloy melted sufficiently. Then the pressure was increased to about $4 \mathrm{GPa}$ as the temperature dropped to $960^{\circ} \mathrm{C}$. After relieving pressure and natural cooling, the final samples were obtained.

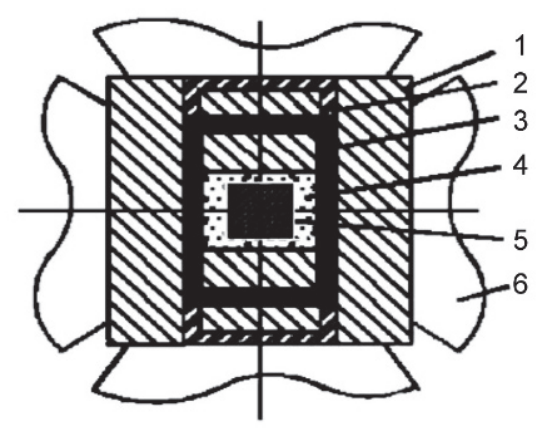

1 - pyrophillite, 2 - conducting ring, 3 - graphite crucible 4 - BN (clad), 5 - specimen, 6 - top ram

Fig. 1: Schematic representation showing specimens in CS-1B type high pressure apparatus
Microstructures of the alloy were observed by means of $\mathrm{OM}$ and SEM. The micro-hardness was measured using HXS1000AY Vivtorinox equipment. Corrosion behavior of the alloys was measured using electro-chemical experiments. Corrosive media was Hank's solution mixed by analytical grade chemicals and distilled water. Electro-chemical polarization experiment was carried out in a standard threeelectrode system. The reference electrode was a saturated calomel electrode, the auxiliary electrode was a platinum electrode and the sample was the working electrode. The scanning speed was $3 \times 10^{-4} \mathrm{~V} \cdot \mathrm{s}^{-1}$. Polarization experiment was carried out in $300 \mathrm{ml} \mathrm{Hank's} \mathrm{solution} \mathrm{at} 37 \pm 1{ }^{\circ} \mathrm{C}$. The samples were sealed with epoxy resin mosaic with an exposed surface area of $1 \mathrm{~cm}^{2}$ and polished with $200^{\#}-1200^{\#}$ sandpapers.

\section{Results and discussion}

\subsection{Microstructure}

\subsubsection{Influence of high pressure on grain size and secondary dendrite arm spacing}

Figure 2 shows the back-scattered electron (BSE) image of the alloys. In contrast to conventional solidification, grain size of the alloy under high pressure is refined from 200$300 \mu \mathrm{m}$ to $100-200 \mu \mathrm{m}$. Figure 3 shows the microstructures of alloys under conventional and high pressure, respectively. For the alloy solidified under high pressure, the secondary dendrite arm becomes more dispersed and refined. The secondary dendrite arm spacing is reduced from $30-50 \mu \mathrm{m}$ to 10-30 $\mu \mathrm{m}$.

Eq. (1) ${ }^{[15]}$ describes the relationship among nucleation energy, pressure and volume changes of the alloy after solidification:

$$
\left[\frac{\partial\left(\Delta G_{V}\right)}{\partial P}\right]_{T}=V^{\alpha}-V^{\beta}=\Delta V
$$

where $G_{V}$ is nucleation energy, $P$ is pressure, $V^{\alpha}$ and $V^{\beta}$ represent solid volume and liquid volume, respectively.

For Mg-8Zn-0.5Zr-0.5Gd alloy, $V^{\beta}$ is larger than $V^{\alpha}$, 

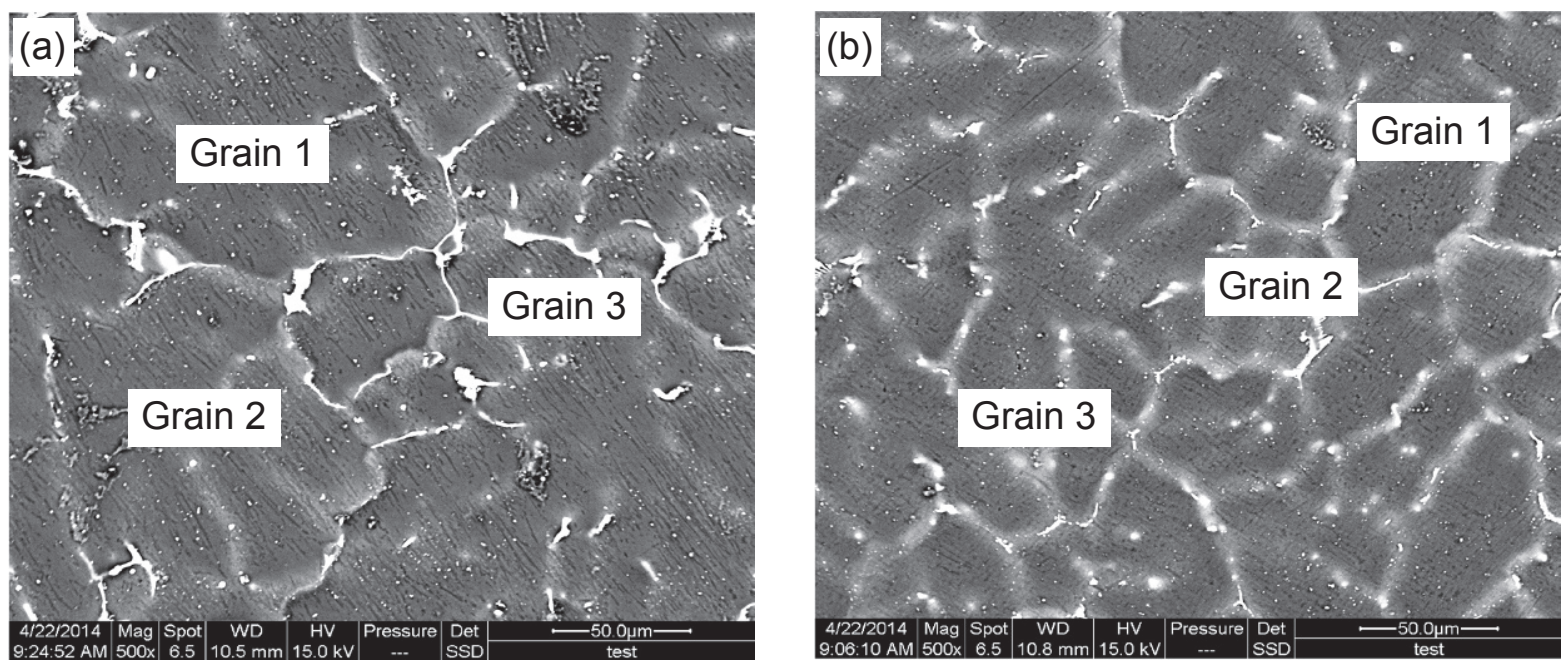

Fig. 2: BSE images of Mg-8Zn-0.5Zr-0.5Gd alloy: (a) conventional solidification and (b) high pressure solidification
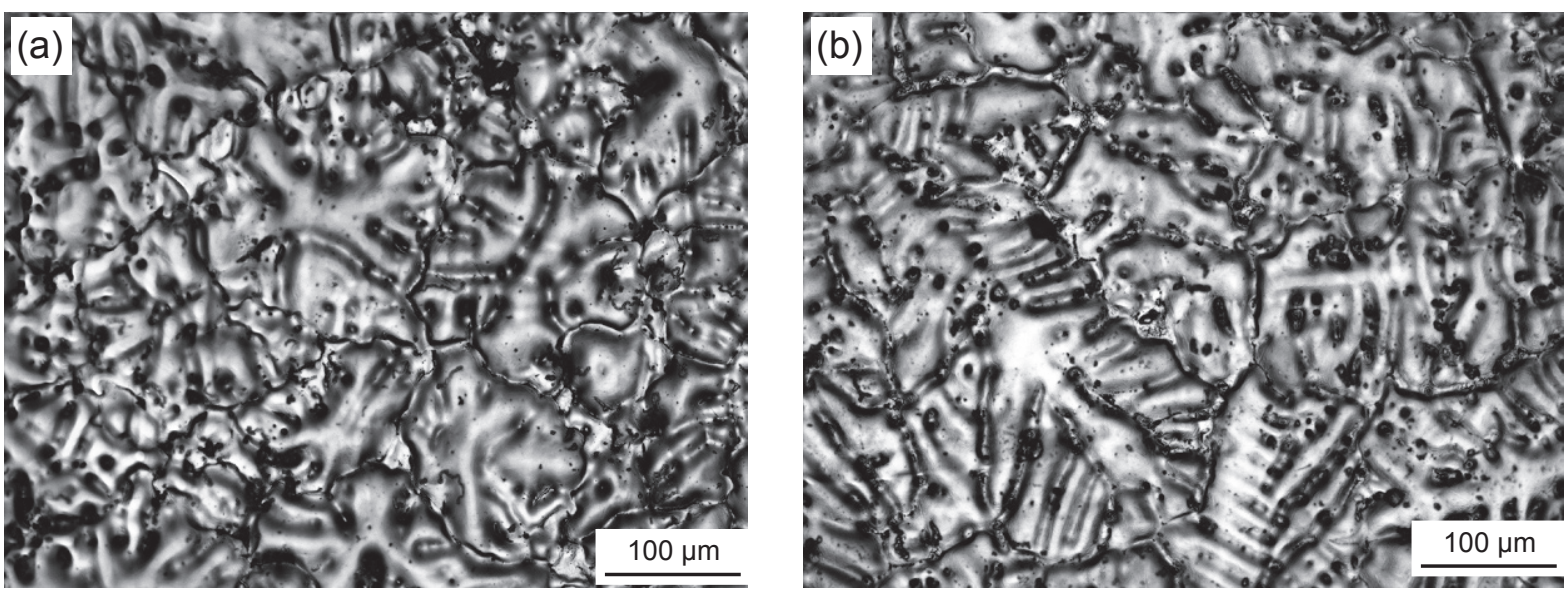

Fig. 3: Microstructure of Mg-8Zn-0.5Zr-0.5Gd alloy: (a) conventional solidification; (b) high pressure solidification

therefore the increase in $P$ under high pressure solidification reduces the critical nucleation energy. Thus the nucleation becomes easier, and the amount of nucleation increases. On the other hand, the high pressure can increase the nucleation rate and degree of supercooling ${ }^{[16-17]}$, which therefore decreases the grain growth rate. The combination of these two factors leads to the grain refinement of the alloy.

The secondary dendrite arm spacing of $\mathrm{Mg}-8 \mathrm{Zn}-0.5 \mathrm{Zr}-$ $0.5 \mathrm{Gd}$ alloys was also obviously refined after high pressure solidification. The reason can be analyzed from the following formulas. The relationship between secondary dendrite arm

$$
d_{2}=A v^{-\frac{1}{3}}
$$

spacing $d_{2}$ and cooling rate $v$ can be obtained ${ }^{[18]}$ :

where $A$ is a constant related to properties of the alloy, and is proportional to diffusion coefficient. When the pressure increased to GPa level, the atomic diffusion in the alloy was strongly inhibited, the diffusion coefficient decreased, so $A$ decreased significantly ${ }^{[19]}$. In this study, for comparison purposes, cooling conditions are the same for the alloy solidified under conventional pressure and high pressure, so the cooling rate $v$ is basically unchanged. Then, according to Eq. 2, when the pressure reaches $4 \mathrm{GPa}, A$ is significantly reduced, leading to the decrease of $d_{2}$, i.e., the refinement of secondary dendrite arm spacing.

\subsubsection{Influence of high pressure on solubility of alloy}

Figures $4 \mathrm{a}$ and $4 \mathrm{~d}$ show the SEM photos of the magnesium alloy by conventional solidification and high pressure solidification. Figures $4 b$ and $4 c$ are the EDS of the matrix (point B) and precipitated phase (area A) in Fig. 4a. Figure 4e shows the EDS of the matrix (C in Fig. 4d). According to EDS results, under conventional solidification, the contents of $\mathrm{Zn}$, $\mathrm{Gd}$, and $\mathrm{Zr}$ in the matrix are 1.90wt.\%, 2.16wt.\%, and 0.35wt.\% (Fig. 4c), respectively. After high pressure solidification, the solid solubility of $\mathrm{Zn}$ and $\mathrm{Zr}$ increases to $2.29 \mathrm{wt} . \%$ and 0.48 wt.\%, while that of Gd decreases to $1.52 \mathrm{wt} \%$ (Fig. 4e). From the view of crystal structure, $\mathrm{Mg}, \mathrm{Zn}$ and Gd have a good compatibility due to the same hexagonal-close-packed (hcp) structure. The atomic radiuses of these three atoms are 173, 135 and $180 \mathrm{pm}$, respectively. Therefore, compared with Gd which has a larger atomic radius, Zn can more easily dissolve into $\alpha-\mathrm{Mg}$ under high pressure, while the solubility of Gd decreases. 

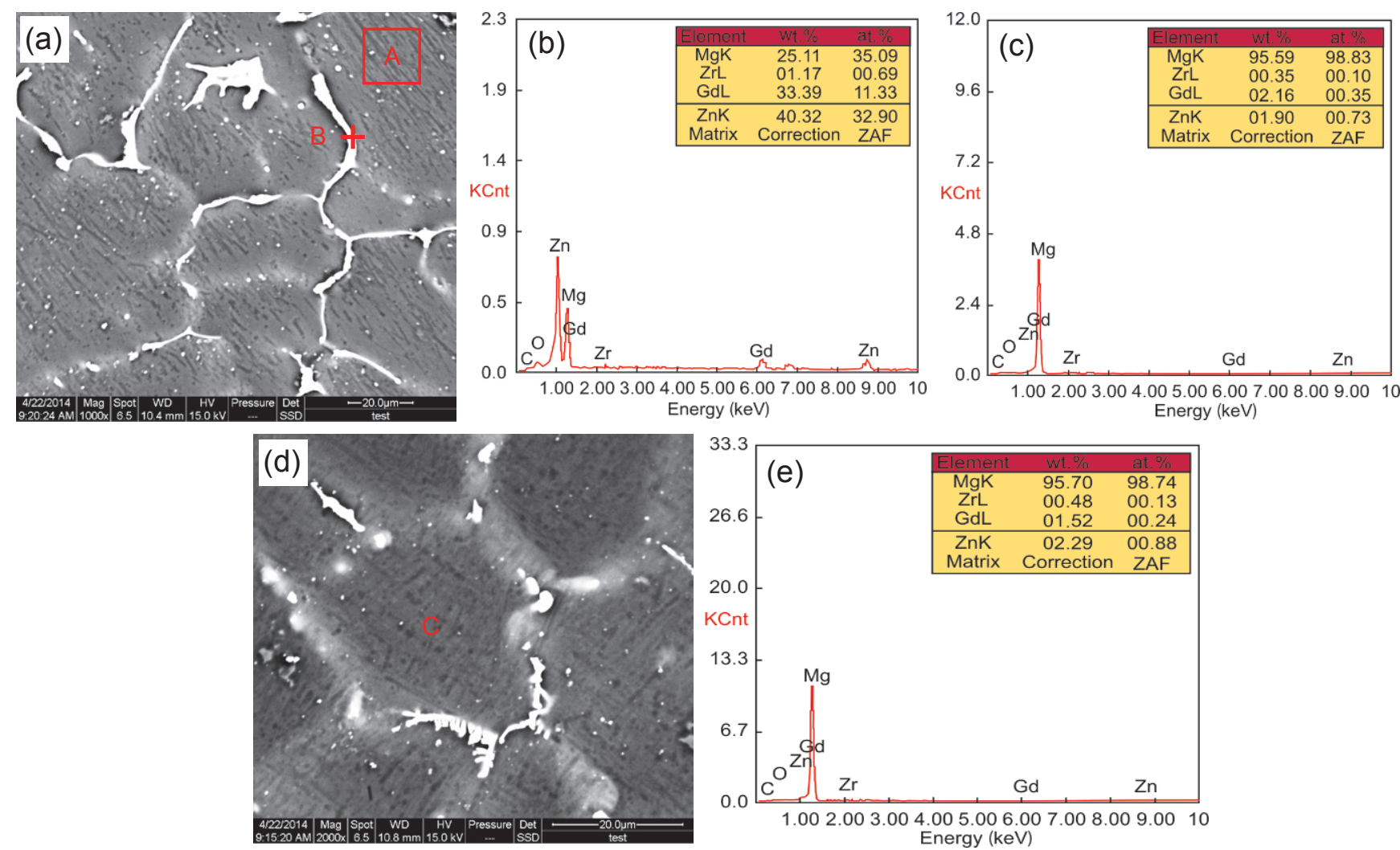

Fig. 4: SEM and EDS results of Mg- $8 \mathrm{Zn}-0.5 \mathrm{Zr}-0.5 \mathrm{Gd}$ alloy: (a) microstructure for conventional solidification, (b) and (c) are EDS results of precipitated phase and matrix in Fig. 4a, (d) microstructure for high pressure solidification, (e) EDS results of matrix in Fig. 4d

\subsubsection{Influence of high pressure on precipitated phase}

As shown in Fig. 4a, under conventional solidification, some second phases with strip shape are distributed at the grain boundary. The strip width is about 1-7 $\mu \mathrm{m}$. As shown in Fig. $4 \mathrm{c}, \mathrm{Mg}, \mathrm{Zn}$, Gd element and a small amount of $\mathrm{Zr}$ can be detected in the precipitated phase. The atomic ratio for $\mathrm{Mg}$, $\mathrm{Zn}, \mathrm{Gd}$ was close to $5: 3: 1$. It was found that $\mathrm{Mg}_{3} \mathrm{Gd}$ exists at the grain boundary of Mg-Gd-Zn ternary alloy ${ }^{[20]}$. Thus, the second phase comprised $\mathrm{Mg}_{2} \mathrm{Zn}_{3}$ and $\mathrm{Mg}_{3} \mathrm{Gd}$ phases.

Compared to conventional solidification, the size and morphology of second phases under high pressure solidification noticeably change as shown in Fig. 4d. Grain size of precipitated phase reduces from $5 \mu \mathrm{m}$ to $2 \mu \mathrm{m}$. At the same time, the second phase changes from long bulky strips to short thin strips and granular shape; and discretely distributes at the grain boundaries.

$\mathrm{XRD}$ results are given in Fig. 5. There are three phases of $\alpha-\mathrm{Mg}, \mathrm{Mg}_{2} \mathrm{Zn}_{3}$ and $\mathrm{Mg}_{3} \mathrm{Gd}$, which are consistent with the EDS results. XRD pattern shows that diffraction peaks of $\mathrm{Mg}_{2} \mathrm{Zn}_{3}$ and $\mathrm{Mg}_{3} \mathrm{Gd}$ significantly reduce after high pressure solidification.

\subsection{Micro-hardness}

The value of micro-hardness of $\mathrm{Mg}-\mathrm{Zn}-0.5 \mathrm{Zr}-0.5 \mathrm{Gd}$ alloy prepared by high pressure solidification $(63.14 \mathrm{HV})$ is larger than that by conventional solidification $(56.17 \mathrm{HV})$. Under conventional solidification, a lot of coarse $\mathrm{Mg}, \mathrm{Zn}$ and $\mathrm{Gd}$ precipitates are mostly distributed along the grain boundaries

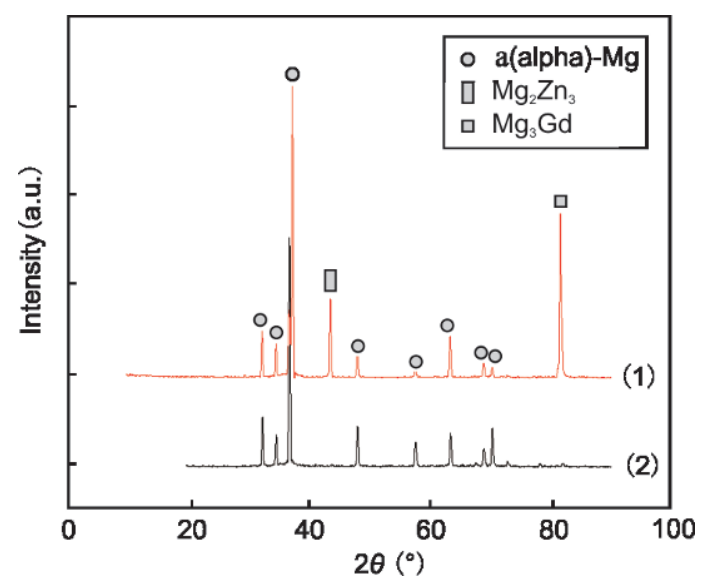

Fig. 5: X-ray patterns of $\mathrm{Mg}-8 \mathrm{Zn}-0.5 \mathrm{Zr}-0.5 \mathrm{Gd}$ alloy by conventional solidification (curve 1) and high pressure solidification (curve 2)

and secondary dendrite. As shown in point A in Fig. 4(a), they are thicker than $1 \mu \mathrm{m}$, some of them even larger than $20 \mu \mathrm{m}$, which has a detrimental effect on strength and hardness. But under high pressure solidification, the precipitates formed on the Mg-8Zn-0.5Zr-0.5Gd alloy matrix become tiny and dispersed, together with the reduction of amount. As shown in Fig. 4d, there are a lot of particle phases under $1 \mu \mathrm{m}$ in size, which can be confirmed as $\mathrm{Mg}_{2} \mathrm{Zn}_{3}$ and $\mathrm{Mg}_{3} \mathrm{Gd}$ phases according to EDX analysis. The $\mathrm{Mg}_{2} \mathrm{Zn}_{3}$ and $\mathrm{Mg}_{3} \mathrm{Gd}$ phases have high hardness ${ }^{[21,22]}$. On the basis of "Orowan" strengthening mechanism, the dislocations which get around these tiny and dispersed precipitates will produce remarkable dislocation multiplication; 
thereby it significantly improves the hardness ${ }^{[23]}$. Thus, microhardness of $\mathrm{Mg}-8 \mathrm{Zn}-0.5 \mathrm{Zr}-0.5 \mathrm{Gd}$ alloy prepared by high pressure solidification is much higher than that of alloy under conventional solidification.

\subsection{Corrosion behavior}

Table 2 shows the values of several electro-chemical characteristics of magnesium alloys. Compared with conventional solidification, both $R_{\mathrm{p}}$ and $E_{\text {corr }}$ of alloy prepared by high pressure solidification are increased. $I_{\text {corr }}$ value decreases. Moreover, the calculated corrosion rate of alloys significantly reduces. It can be seen from Figs. $4 \mathrm{~b}$ and $4 \mathrm{e}$, the solid solubility of $\mathrm{Zn}$ increases significantly in the matrix during the solidification under high pressure, which improves the stability of the passivation membrane ${ }^{[24]}$, and therefore improves the corrosion resistance of the alloy. In addition, it is known that the galvanic corrosion of granular phase and matrix is one of the main reasons for the corrosion of magnesium alloy ${ }^{[25]}$. While it can be seen from Figs. 4a and 4d, compared to conventional solidification, the size of precipitation phase under high pressure solidification reduces significantly, which therefore decreases the galvanic corrosion effect on the alloy matrix, thus improving the corrosion behavior of the alloy.

Table 2: Electro-chemical parameters of Mg-8Zn-0.5Zr-0.5Gd alloy

\begin{tabular}{ccccc|} 
Alloy & $E_{\text {corr }}(\mathrm{V})$ & $\boldsymbol{I}_{\text {corr }}\left(\boldsymbol{\mu A} \cdot \mathrm{cm}^{-2}\right)$ & $\boldsymbol{R}_{\mathrm{p}}(\mathbf{k} \Omega \mathrm{hm})$ & $\begin{array}{c}\text { Corrosion rate } \\
(\mathbf{m m} \cdot \mathbf{y e a r})\end{array}$ \\
\hline Solidified under conventional pressure & -1.45 & 280 & 1.706 & 4.0 \\
Solidified under high pressure & -1.44 & 230 & 2.043 & 2.7
\end{tabular}

\section{Conclusions}

(1) High pressure solidification (4 GPa) can significantly refine the grain size of $\mathrm{Mg}-8 \mathrm{Zn}-0.5 \mathrm{Zr}-0.5 \mathrm{Gd}$ alloy from $200-$ $300 \mu \mathrm{m}$ to $100-200 \mu \mathrm{m}$ and reduce the secondary dendrite arm spacing from 30-50 $\mu \mathrm{m}$ to $10-30 \mu \mathrm{m}$. Under high pressure, the critical nucleation energy of the alloy is decreased, thus the nucleation becomes easier, and the amount of nucleation increases. On the other hand, the high pressure can increase the nucleation rate and degree of supercooling ${ }^{[16]}$, which therefore decreases the grain growth rate. The combination of these two factors leads to the grain refinement.

(2) High pressure solidification significantly increases the microhardness of Mg-8Zn-0.5Zr-0.5Gd alloy from 56.17 $\mathrm{HV}$ to $63.14 \mathrm{HV}$. The tiny and dispersed $\mathrm{Mg}_{2} \mathrm{Zn}_{3}$ and $\mathrm{Mg}_{3} \mathrm{Gd}$ precipitates under high pressure solidification contribute to the increase of micro-hardness.

(3) High pressure solidification increases the corrosion resistance of $\mathrm{Mg}-8 \mathrm{Zn}-0.5 \mathrm{Zr}-0.5 \mathrm{Gd}$ alloy effectively. The corrosion rate decreases from $4.0 \mathrm{~mm} \cdot$ year $^{-1}$ to $2.7 \mathrm{~mm} \cdot \mathrm{year}^{-1}$. The solidification under high pressure increases the solid solubility of $\mathrm{Zn}$ in the alloy, which increases the stability of the passivation membrane, and at the same time, the decrease of precipitated phase size solidified under high pressure reduces the galvanic corrosion strength. Their combined action results in the corrosion resistance improvement of the alloy.

\section{References}

[1] Staigera M P, Pietaka A M. Magnesium and its alloys as orthopedic biomaterials: A review. Biomaterials, 2006, 27(9): 1728-1734.

[2] Zheng Yufeng, Gu Xuenan, Li Nan, et at. Development and Prospects of Biodegradable Magnesium Alloys. Materials China, 2011, 30(4): 30-33. (In Chinese)
[3] Tan Lili, Yu Xiaoming, Wan Peng, et al. Biodegradable Materials for Bone Repairs: A review. Journal of Materials Science \& Technology, 2013, 29(6): 503-513.

[4] Gu Xuenan, Zheng Yufeng, Cheng Yan, et al. In vitro corrosion and bio-compatibility of binary magnesium alloys. Biomaterials, 2009, 30: 484-498.

[5] Gao Jiacheng, Wu Sha, Qiao Liying, et al. Corrosion behavior of $\mathrm{Mg}$ and $\mathrm{Mg}-\mathrm{Zn}$ alloys in simulated body fluid. Transactions Nonferrous Metals Society of China, 2008, 18: 589-590.

[6] Yin Dongsong, Zhang Erlin and Zeng Songyan. Effect of extrusion on mechanical properties and corrosion behavior of Mg-Mn-Zn alloy. Acta of Materials Heat Treatment, 2009, 30(1): 114-116. (In Chinese)

[7] Wu Ruizhi and Zhang Milin. Microstructure, Mechanical Properties and Aging Behavior of Mg-5Li-3Al-2Zn-xAg. Materials Science and Engineering A, 2009, 520: 36-39.

[8] Paszkowicz W. High-pressure powder X-ray diffraction at the turn of the century. Nuclear Instruments and Methods in Physics Research B, 2002, 198: 142-144.

[9] Emmnauel S, Paul F M and Clivia H. Pressure-induced Transformations $\alpha-$ and $\beta-\mathrm{Ge}_{3} \mathrm{~N}_{4}$ : In situ Studies Sychrotoron X-ray diffraction. Journal of Solid State Chemistry, 2004, 177: 299.

[10] Lin Xiaoping, Dong Yun, Xu Rui, et al. Solidification Microstructures and Crystalline Morphologies of Mg-6Zn-Y Alloy Solidified Under GPa Level Super-High Pressure. Rare Metal Materials and Engineering, 2013, 42(11): 2310-2312.

[11] Lin Xiaoping, Dong Yun, Xu Rui, et al. Crystal Morphologies and the phases in the $\mathrm{Mg}-6 \mathrm{Zn}-3 \mathrm{Y}$ alloy solidified under superhigh pressure. Acta Metallurgica Sinica, 2011, 42(12): 15501554.

[12] Wang Jianqing, Li Nai-peng, Yang Hong-bo, et al. Effects of high pressure treatment on microstructure and mechanics properties of AZ91D alloy. Journal of Yanshan University, 2012, 12(6): 497-499. (In Chinese)

[13] Zhao Shuangshuang, Peng Qiuming, Li Hui, et al. Effects of super-high pressure on microstructures, nano-mechanical behaviors and corrosion properties of Mg-Al alloys. Journal of Alloys and Compounds, 2014, 584: 56-62.

[14] Peng Qiuming, Zhao Shuangshuang, Li Hui, et al. High Pressure Solidification: An Effective Approach to Improve the 
Corrosion Properties of Mg-Y Based Implants. International Journal of Electrochemical Science, 2012, 7: 5581-5595.

[15] Wang Haiyan, Liu Riping, Ma Mingzhen, et al. Solidification of $\mathrm{FeSi}_{2}$ alloy under high pressure. Chinese Journal of Physics, 2004, 53(7): 2378-2380.

[16] Wang Zhenling. Investigation on evolution of microstructure and phase in Al-Mg alloy solidifying under high pressure. Ph.D. Dissertation. Harbin: Harbin Institute of Technology, 2007: 1113, 32-33, 81-83. (In Chinese)

[17] Qu Yingdong, Wang Yubin, Cao Xiusheng, et al. Distribution rule of solute $\mathrm{Al}$ in ZA alloy under ultra-high pressure. Journal of Shenyang University of Technology, 2012, 32(4): 381-383. (In Chinese)

[18] Hu Hanqi. Metal solidification principle. Beijing: China Machine Press, 1984: 26-34. (In Chinese)

[19] Hu Zhuanglin. Metastable Metallic Materials. Beijing: Science Press, 2006, 58-60. (In Chinese)

[20] Guo Lianping, Chen Leping, Yin Jian, et al. Effcets of Zn Contents on Microstructures and Properties of Mg-Gd-Zn
Alloys. Foundry Technology, 2013, 34(2): 129-131.

[21] Li Jiehua, Jie Wanqi, Yang Guangyu. Effect of Gadolinium on Microstructure and the Mechanical Properties of Mg-Zn-Zr Cast Magnesium Alloys. Rare Metal Materials and Engineering, 2008, 37(9): 1587-1589. (In Chinese)

[22] Rokhlin L L. Magnesium alloys containing rare earth metals: structure and properties. London: Taylor \& Francis, 2003: 97-99.

[23] Chen Jian-feng, Wu Gao-hui, Sun Dong-li, et al. Strengthening mechanisms of metal matrix composites. Journal of Aeronautical Materials, 2002, 22(2): 49-51. (In Chinese)

[24] Yin Dongsong, Zhang Erlin, Zeng Songyan. Effect of Zn on mechanical properties and corrosion properties of as-cast $\mathrm{Mg}$ Mn alloy. The Chinese Journal of Nonferrous Metals, 2008, 18(3): 388-342. (In Chinese)

[25] Li Xin, Jiang Jing-hua, Zhao Yong-hao. Effect of equal-channel angular pressing and aging on corrosion behavior of ZK60 Mg alloy. Trans. Nonferrous Met. Soc. China, 2015 (25): 39093920 